\title{
Modelling Gas Adsorption in Porous Solids: Roles of Surface Chemistry and Pore Architecture
}

\author{
SATYANARAYANA BONAKALA and SUNDARAM BALASUBRAMANIAN* \\ Chemistry and Physics of Materials Unit, Jawaharlal Nehru Centre for Advanced Scientific Research, \\ Bangalore 560 064, India \\ e-mail: bala@jncasr.ac.in
}

MS received 18 May 2015; revised 29 June 2015; accepted 16 July 2015

\begin{abstract}
Modelling the adsorption of small molecule gases such as $\mathrm{N}_{2}, \mathrm{CH}_{4}$ and $\mathrm{CO}_{2}$ in porous solids can provide valuable insights for the development of next generation materials. Employing a grand canonical Monte Carlo simulation code developed in our group, the adsorption isotherms of $\mathrm{CH}_{4}$ and $\mathrm{CO}_{2}$ in many metal organic frameworks have been calculated and compared with experimental results. The isotherms computed within a force field approach are able to well reproduce the experimental data. Key functional groups in the solids which interact with gas molecules and the nature of their interactions have been identified. The most favorable interaction sites for $\mathrm{CH}_{4}$ and $\mathrm{CO}_{2}$ in the framework solids are located in the linkers which are directed towards the pores. The structure of a perfluorinated conjugated microporous polymer has been modelled and it is predicted to take up $10 \%$ more $\mathrm{CO}_{2}$ than its hydrogenated counterpart. In addition, the vibrational, orientational and diffusive properties of $\mathrm{CO}_{2}$ adsorbed in the solids have been examined using molecular dynamics simulations. Intermolecular modes of such adsorbed species exhibit a blue shift with increasing gas pressure.
\end{abstract}

Keywords. Monte Carlo simulations; metal organic frameworks; Grand Canonical Monte Carlo; adsorption isotherm.

\section{Introduction}

Adsorption of gases in porous solids has received a lot of attention over the past several decades not only from a fundamental point of view, but also towards many applications including the development of efficient and environmentally benign energy materials. ${ }^{1}$ Materials for storage of gases such as $\mathrm{H}_{2},{ }^{2-4} \mathrm{O}_{2},{ }^{5}$ and $\mathrm{CH}_{4}{ }^{6-8}$ are important in energy applications and that for $\mathrm{CO}_{2}{ }^{9,10}$ in the environmental domain. Both volumetric and gravimetric ${ }^{11-14}$ uptake by a substance are important quantities to judge its applicability for gas storage. Apart from pore size, pore volume and surface area of the adsorbent, ${ }^{15,16}$ gas uptake is strongly influenced by its chemical characteristics, ${ }^{17}$ the accessibility of its pores to the gas molecule and temperature. ${ }^{18-21}$

Modelling of adsorption isotherms is essential to develop a microscopic understanding of gas adsorption and gas-solid interactions. Various computational techniques have been adopted to model gas adsorption and separation of gases using porous solids. For a comprehensive review, see Ref. ${ }^{22}$ One of the important modelling methods for studying adsorption is the grand canonical Monte Carlo (GCMC) simulation,

*For correspondence carried out in the constant $\mu \mathrm{VT}$ ensemble. The average number of molecules adsorbed as a function of pressure, i.e., the adsorption isotherm can be obtained from a GCMC simulation. ${ }^{23-36}$ While several open source Monte Carlo simulation programs are available such as the MCCCS Towhee, ${ }^{37}$ Etomica, ${ }^{38}$ BOSS, ${ }^{39}$ DL_MONTE ${ }^{23}$ and MUSIC. ${ }^{40}$ Results reported here are obtained through a code developed in-house called MCIN.

In the present work, we focus on studying the adsorption of $\mathrm{CO}_{2}$ and $\mathrm{CH}_{4}$ in many metal organic framework (MOF) solids. The MOFs considered here are well characterized experimentally, both in terms of crystal structure and through adsorption isotherms for either $\mathrm{CH}_{4}$ and/or $\mathrm{CO}_{2}$. They possess different organic linker groups with varied functionalities. Thus, one can obtain a microscopic rationalization of gas uptake in these systems, an aspect which has not yet been studied using simulations. In addition, we have also examined the adsorption of $\mathrm{CO}_{2}$ in a yet to be synthesized, perfluorinated amorphous polymer. One of the key results that have emerged from our investigations is that for a proper reproduction of experimental isotherms, consideration of electrostatic interactions between $\mathrm{CO}_{2}$ molecules is necessary while that of the same between the gas and the framework appears not to be as relevant. 
We have also been able to predict an increased uptake of $\mathrm{CO}_{2}$ by an amorphous polymer upon its perfluorination. The manuscript is divided as follows. Following this Introduction, we present details of the simulations of gas adsorption in several MOFs and of modelling the amorphous polymer. Subsequently, results from the simulations are presented, followed by conclusions drawn.

\section{Computational details}

\subsection{GCMC Simulations using MCIN}

Details of implementation of the GCMC code, its capabilities and validation are provided in Supplementary Information. Here, we provide the setup, potentials and other run details for each of the system studied. The adsorbents chosen have been well studied experimentally in terms of structure and gas $\left(\mathrm{CH}_{4}\right.$ or $\left.\mathrm{CO}_{2}\right)$ adsorption characteristics.

2.1a $\mathrm{CH}_{4}$ adsorption: We studied the adsorption isotherms of $\mathrm{CH}_{4}$ in FMOF-1, $\left(\mathrm{Ag}_{2}\left[\mathrm{Ag}_{4} \mathrm{Tz}_{6}\right]\right)_{\mathrm{n}}$, where $\mathrm{Tz}=3,5$-bis (trifluoromethyl) $[1,2,4 \text { - triazolate }]^{41}$ and $\left[\mathrm{Zn}_{2}(\mathrm{~L})\right]_{\infty}, \mathrm{L}=4,4^{\prime}$-bipyridine-2,6,2'42 MOF. FMOF1 is quite hydrophobic due to perfluorinated ligands and exhibits a high uptake of hydrocarbons over water vapour. ${ }^{43}\left[\mathrm{Zn}_{2}(\mathrm{~L})\right]_{\infty}$ is demonstrated to show tremendous thermal stability and reversible uptake of several organics. ${ }^{42}$ A cutoff distance of $12.8 \AA$ was used for LJ interactions. Cavity biased GCMC simulations were carried out (see Supporting Information for details). Framework atoms were treated using the universal force field (UFF) ${ }^{44}$ and $\mathrm{CH}_{4}$ molecule was considered as a single LJ interaction site with parameters taken from the TraPPE force field. ${ }^{45}$ Thus, rotational moves for the adsorbate were not necessary. At each state point, the GCMC simulation consisted of $1 \times 10^{7}$ steps devoted towards equilibration followed by $2 \times 10^{8}$ steps to sample the desired thermodynamic properties. Values of $0.8 \sigma$ and $0.5 \sigma$ were used as cavity radii at low and higher pressures respectively. The details of the GCMC simulations are tabulated in table 1 .

\section{2 $\mathrm{CO}_{2}$ adsorption}

2.2a $Z n(N D C)(D M B I) \quad M O F$ : We performed GCMC simulations using MCIN to study the adsorption isotherms of $\mathrm{CO}_{2}$ in a microporous framework, $\mathrm{Zn}(\mathrm{NDC})(\mathrm{DPMBI}) \quad$ (where $\mathrm{NDC}=2,7$-naphthalene dicarboxylate and DPMBI $=\mathrm{N}, \mathrm{N}$ '-di-(4-pyridylmethyl) -1,2,4,5-benzenetetracarboxydiimide). ${ }^{46} \mathrm{Zn}$ (NDC)(DPMBI) exhibits selective $\mathrm{CO}_{2}$ capture from flue gas. ${ }^{46}$ An orthorhombic supercell of $1 \times 2 \times 2$ unit cells was taken as the simulation box and its dimensions were $25.915 \AA \times 28.3488 \AA \times 41.2084 \AA$. Here too, the TraPPE force field with LJ and charge sites ${ }^{47}$ was considered for $\mathrm{CO}_{2}$. While the gas-gas interactions included both LJ and Coulombic terms, that between the gas and the framework was treated using purely LJ interactions through the DREIDING ${ }^{48}$ and $\mathrm{UFF}^{44}$ force fields. Electrostatic interactions were calculated using Ewald summation method. Cross LJ parameters were calculated via the Lorentz-Berthelot mixing rule. Framework atoms were considered as frozen in their crystallographic positions. The force field parameters of framework atoms are provided in table S3. A cutoff radius of $12.8 \AA$ was used for $\mathrm{LJ}$ interactions. The Peng-Robinson equation of state was used to convert pressure into chemical potential. In this case, the fugacity coefficients at a particular pressure and temperature were calculated using Thermosolver software. ${ }^{49} \mathrm{We}$ performed $4 \times 10^{7}$ cycles subsequent to $1 \times 10^{7}$ cycles which were devoted to equilibration.

2.2b Perfluorinated Amorphous Polymer: We had recently modelled the structure and gas adsorption characteristics of a conjugated microporous amorphous polymer based on tetraphenylethylene moieties. ${ }^{50}$ In the current work, we examine theoretically the effect of perfluorinating this compound on its properties. The methodology adopted to create a model for this fluorinated compound is the same as that described in Ref. ${ }^{50}$. Further details are provided in Supplementary Information.

It is pertinent to note that the framework (adsorbent) has been treated to be rigid in the simulations reported

Table 1. Simulation details of $\mathrm{CH}_{4}$ adsorption studies in FMOF-1 and $\left[\mathrm{Zn}_{2}(\mathrm{~L})\right]_{\infty}$ MOF. Both are orthorhombic systems.

\begin{tabular}{lccc}
\hline MOF & Cell parameters & Simulation cell ccell & Temperature (K) \\
\hline FMOF-1 & $\mathrm{a}=\mathrm{b}=13.366 \AA$ & $2 \times 2 \times 1$ & 288 \\
{$\left[\mathrm{Zn}_{2}(\mathrm{~L})\right]_{\infty}$ MOF } & $\mathrm{a}=\mathrm{b}=7.025 \AA$ & $4 \times 4 \times 2$ & 298 \\
\hline
\end{tabular}


here. The organic linkers in MOF solids can in particular exhibit conformational flexibility which can modulate gas uptake. Introducing flexibility in the framework within the MCIN code is beyond the scope of the current manuscript. However, this aspect will be studied by us in future, using methods such as hybrid GCMC/MD.${ }^{51-55}$ Configurations were visualized using VMD. ${ }^{56}$

\section{Results and Discussion}

In order to assess whether the widely used generic force fields are able to describe the adsorbate-adsorbent interactions accurately, we have studied the adsorption of $\mathrm{CO}_{2}$ in porous materials (two MOFs and one CMP) with both DREIDING and UFF force fields. Pair correlation functions have been calculated to delineate the intermolecular arrangements of adsorbed $\mathrm{CH}_{4}$ and $\mathrm{CO}_{2}$ as well as their favorable interaction sites within the MOF framework as a function of gas pressure. Specific structural details of the various MOFs are not described here as they can be obtained from the original literature.

\subsection{Adsorption Isotherm of $\mathrm{CH}_{4}$}

3.1a FMOF-1: The adsorption isotherm calculated from MCIN is compared with experimental data ${ }^{43}$ in figure 1a. To delineate the most favorable adsorption sites for $\mathrm{CH}_{4}$ in the framework, pair correlation functions (PCFs) were calculated between the molecule and different sites of MOF. F-CH $, \mathrm{N}_{4}-\mathrm{CH}_{4}, \mathrm{C}-\mathrm{CH}_{4}$ and $\mathrm{Ag}$ $\mathrm{CH}_{4}$ PCFs were calculated at 1, 45 and 200 bar. PCFs for various sites at 1 bar (low pressure) are compared in figure 2a. Closest interactions for $\mathrm{CH}_{4}$ were observed with the $\mathrm{F}$ atoms of the $-\mathrm{CF}_{3}, \mathrm{~N}$ and $\mathrm{C}$ atoms of the 1,2,4-triazole. Thus, further studies have been focused on these three interactions. The PCFs of $\mathrm{CH}_{4}$ molecules around $\mathrm{F}, \mathrm{N}, \mathrm{C}$ of the MOF and other $\mathrm{CH}_{4}$ molecules at 1 bar, 45 bar and 200 bar in figure S22a-c respectively.
In figure $\mathrm{S} 22 \mathrm{a}$, three features at $3.5 \AA, 4.3 \AA$, and $5.1 \AA$ are seen. The first hump corresponds to the $\mathrm{CH}_{4}$ interacting with a $\mathrm{F}$ atom of $-\mathrm{CF}_{3}$ which is directed towards the pore and the remaining two correspond to the other two $\mathrm{F}$ atoms in the same $\mathrm{CF}_{3}$ group. In figure $\mathrm{S} 22 \mathrm{~b}$ and $\mathrm{c}$, the first hump corresponds to correlation between one of the $\mathrm{N}$ and $\mathrm{C}$ atoms of 1,2,4-triazole and the remaining correspond to other $\mathrm{N}$ and $\mathrm{C}$ atoms in the same group. We observe that although the relative magnitudes of the peaks are impacted by pressure, the peak positions are not. The peak heights increase with increasing pressure, as expected. The interactions exhibited by $\mathrm{CH}_{4}$ with FMOF-1 atoms at 1 bar and $288 \mathrm{~K}$ are displayed in figure $2 b$.

3.1b $\left[Z n_{2}(L)\right]_{\infty}$ MOF: The adsorption isotherm of $\mathrm{CH}_{4}$ simulated using MCIN is compared with experimental data ${ }^{42}$ in figure $1 \mathrm{~b}$. Here too, PCFs are calculated to identify favorable interaction sites for $\mathrm{CH}_{4}$ in MOF. The C- $\mathrm{CH}_{4}, \mathrm{H}-\mathrm{CH}_{4}$ and $\mathrm{O}-\mathrm{CH}_{4}$ PCFs were calculated at 0.5 bar, 4 bar, 10 bar and $298 \mathrm{~K}$ and the same are compared at low pressure in figure $3 \mathrm{a}$. The closest possible interactions for $\mathrm{CH}_{4}$ are with the $\mathrm{H}$ and $\mathrm{O}$ atoms of 2, 2'-bipyridyl-5, 5'-dicarboxylic linker of the framework. We have compared PCFs and corresponding first shell coordination numbers of $\mathrm{H}-\mathrm{CH}_{4}$ as well as $\mathrm{O}-\mathrm{CH}_{4}$ at $0.5,4$ and $10 \mathrm{bar}$ and at $298 \mathrm{~K}$ as shown in figure $\mathrm{S} 23 \mathrm{a}-\mathrm{b}$. In figure $\mathrm{S} 23 \mathrm{a}$, the peak at $3.4 \AA$ represents $\mathrm{CH}_{4}$ interaction with the two $\mathrm{H}$ atoms of 2,2'-bipyridyl-5,5' - dicarboxylic group. In figure S23b, two prominent peaks centered at $3.6 \AA$ and $6.0 \AA$ are observed. The first one corresponds to the $\mathrm{CH}_{4}$ interacting with the $\mathrm{O}$ atom of the carboxylate group of the linker. The second peak corresponds to $\mathrm{CH}_{4}$ interacting with the $\mathrm{O}$ atoms of adjacent linker within the same pore. These interactions are depicted in figure $3 b$. The peak heights in the PCFs increase with increasing pressure, as expected. The number of $\mathrm{CH}_{4}$ molecules near a $\mathrm{H}$-atom of the MOF is around 1.1 at a pressure of 45
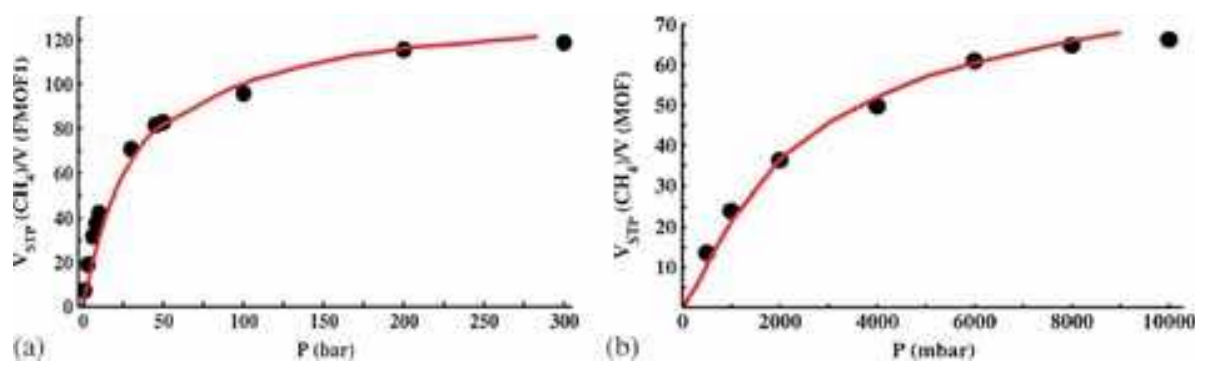

Figure 1. Comparison of adsorption isotherm of $\mathrm{CH}_{4}$ in a) FMOF-1; and b) $\left[\mathrm{Zn}_{2}(\mathrm{~L})\right]_{\infty}$ MOF obtained from MCIN (black circles) at $288 \mathrm{~K}$ and $298 \mathrm{~K}$ with experimental data (continuous line). ${ }^{42,43}$ 

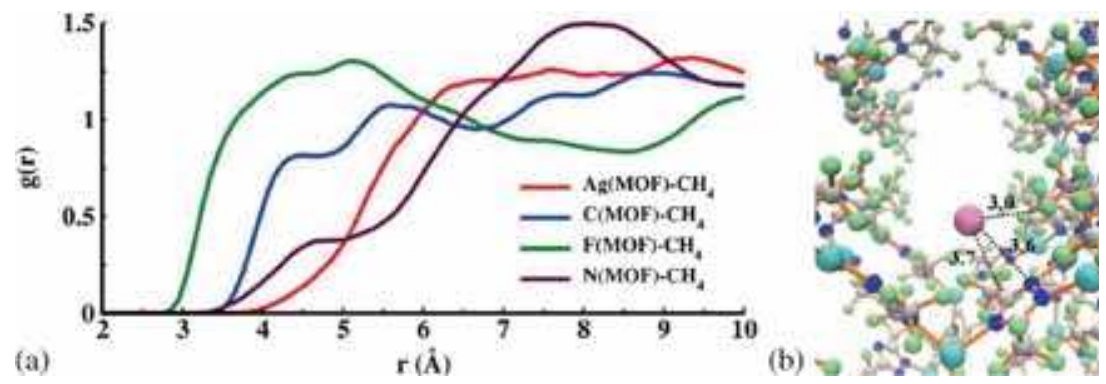

Figure 2. a) Comparison of pair correlation functions between different types of atoms of FMOF-1 and $\mathrm{CH}_{4}$ at 1 bar and $288 \mathrm{~K}$. b) Primary interactions for $\mathrm{CH}_{4}$ in FMOF-1 at 1 bar and $288 \mathrm{~K}$. Distances are in $\AA$ unit. Color scheme: $\mathrm{C}$-silver, $\mathrm{H}$-lime, $\mathrm{N}$-blue, $\mathrm{Ag}$-cyan and $\mathrm{CH}_{4}$-mauve.


Figure 3. a) Comparison of the pair correlation functions between different types of atoms of $\left[\mathrm{Zn}_{2}(\mathrm{~L})\right]_{\infty} \mathrm{MOF}$ and $\mathrm{CH}_{4}$ at 0.5 bar and $298 \mathrm{~K}$. b) Primary interactions for $\mathrm{CH}_{4}$ in the $\left[\mathrm{Zn}_{2}(\mathrm{~L})\right]_{\infty} \mathrm{MOF}$ at 0.5 bar and $298 \mathrm{~K}$. Distances are in $\AA$ unit. Color scheme: C-silver, $\mathrm{H}$-lime, O-red, and $\mathrm{CH}_{4}$-iceblue.

bar and does not increase much further with increase in pressure.

\subsection{Adsorption Isotherms of $\mathrm{CO}_{2}$}

3.2a IRMOF-1: Simulations in this MOF were carried out to validate the MCIN code, as described in Supplementary Information. The calculated adsorption isotherm of $\mathrm{CO}_{2}$ at $298 \mathrm{~K}$ is compared in figure $\mathrm{S} 8$ with the simulation results of Snurr et al. ${ }^{57}$ and the isotherms determined from experiment. ${ }^{57}$ Figure $\mathrm{S} 8$ shows that the predicted uptake using LJ interactions alone is considerably lower than the experimental result. Inclusion of coulombic interactions between the gas molecules is able to estimate the saturated loading in much better agreement with experiment. More importantly, it captures the inflection behavior. Our GCMC results agree well with those of Snurr and coworkers. ${ }^{57}$ It should be noted that the inflection is captured without invoking any charges in the MOF structure itself. Figure S8 clearly shows the importance of electrostatic interactions between $\mathrm{CO}_{2}$ molecules to reproduce the shape of the experimental adsorption isotherm. The marginal difference with experimental $\mathrm{CO}_{2}$ uptake could be due to (i) deficiencies in the potential, (ii) the morphology of the experimental MOF sample may impose a kinetic barrier which can result in a lower uptake than the theoretical estimate. ${ }^{58}$

The intermolecular arrangement of adsorbed $\mathrm{CO}_{2}$ molecules as well as favorable interaction sites for $\mathrm{CO}_{2}$ with the IRMOF-1 have been studied based on PCFs between different pairs of atoms. Several PCFs were calculated at $298 \mathrm{~K}$ and 4, 10 and $20 \mathrm{~atm}$. The intermolecular PCFs between adsorbed $\mathrm{CO}_{2}$ molecules at three pressures are shown in figure 4 . The peak heights of $\mathrm{g}_{\mathrm{C}-\mathrm{C}}(\mathrm{r})$ and $\mathrm{g}_{\mathrm{C}-\mathrm{O}}(\mathrm{r})$ increase with increasing pressure. Based on the PCFs of $\mathrm{CO}_{2}$ with MOF atoms obtained at low pressure ( $4 \mathrm{~atm})$, the following interactions can be identified between adsorbed $\mathrm{CO}_{2}$ and IRMOF-1: (i) $\mathrm{O}$ of $\mathrm{CO}_{2}$ and $\mathrm{H}$ of the phenyl rings of IRMOF-1 (weak hydrogen bond interaction), (ii) $\mathrm{C}$ of $\mathrm{CO}_{2}$ and $\mathrm{O}$ of carboxylate groups of IRMOF-1 (Lewis acid-base interaction), and (iii) center of mass of phenyl rings and the $\mathrm{C}$ atom of the $\mathrm{CO}_{2}(\pi-\pi$ interaction). Given the absence of electronic degrees of freedom in our simulations, these interactions have been identified on established geometric criteria alone. ${ }^{59-62}$ These PCFs have been calculated at 4, 10 and 20 atm and are shown in figure 5a-c. In figure 5a, two peaks 



Figure 4. Intermolecular pair correlation functions between sites of adsorbed $\mathrm{CO}_{2}$ molecules in IRMOF-1 a) C-C and b) C-O at $298 \mathrm{~K}$ and $4 \mathrm{~atm}, 10 \mathrm{~atm}$, and $20 \mathrm{~atm}$.

(a)

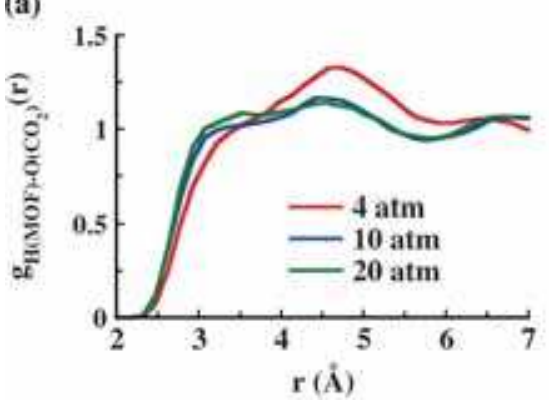

(b)

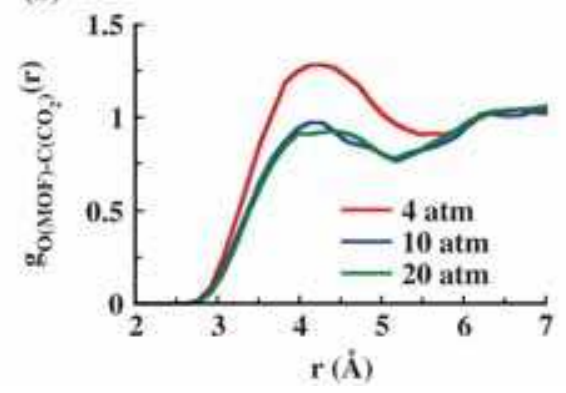

(c)

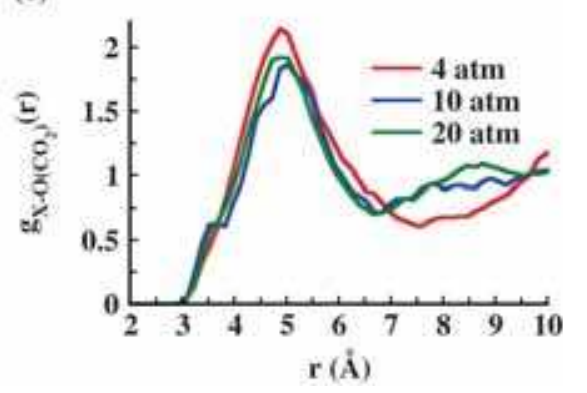

Figure 5. Pair correlation functions between a) $\mathrm{H}$ of $\mathrm{MOF}$ and $\mathrm{O}$ of $\mathrm{CO}_{2}$; b) $\mathrm{O}$ of $\mathrm{MOF}$ and $\mathrm{C}$ of $\mathrm{CO}_{2}$; and c) center of mass of phenyl ring $(\mathrm{X})$ and $\mathrm{O}$ of $\mathrm{CO}_{2}$ at $298 \mathrm{~K}$ and $4 \mathrm{~atm}, 10 \mathrm{~atm}$, and $20 \mathrm{~atm}$. The MOF is IRMOF-1.

can be found at $3.2 \AA$ and $4.6 \AA$. The first one corresponds to the interaction of $\mathrm{O}$ of $\mathrm{CO}_{2}$ with one of the $\mathrm{H}$ of phenyl ring while the other corresponds to the interaction of $\mathrm{CO}_{2}$ with the other $\mathrm{H}$ of the adjacent phenyl ring within the same pore. In figure $5 \mathrm{~b}$, the peak at $4.2 \AA$ corresponds to the $\mathrm{C}$ of $\mathrm{CO}_{2}$ interacting with the $\mathrm{O}$ of carboxylate group of IRMOF-1. Although the coordination number increases with pressure (as it should), the magnitude of the peak (which is the probability density) decreases with increasing pressure. At higher pressures, $\mathrm{CO}_{2}$ prefers to adsorb in the pores by interacting with $\mathrm{H}$ of phenyl rings which is the entropically dominant zone. ${ }^{63}$ The first shell coordination number of $\mathrm{C}$ of $\mathrm{CO}_{2}$ around the $\mathrm{O}$ of carboxylate group of IRMOF-1 as a function of pressure is plotted in figure $\mathrm{S} 24$. This behavior is analogous to the adsorption isotherm (blue curve in figure S8). The number of $\mathrm{CO}_{2}$ molecules present near $\mathrm{O}$ of carboxylate group of IRMOF-1 at $12 \mathrm{~atm}$ is 2.7 and does not change much, with increase in gas pressure. In figure $5 \mathrm{c}$, the peak at $5 \AA$ corresponds to the $\pi-\pi$ interaction between phenyl ring of IRMOF- 1 and $\mathrm{CO}_{2}$. Here too, the peak height decreases with increasing pressure as $\mathrm{CO}_{2}$ prefers to adsorb in the entropically dominant site. The interactions between $\mathrm{CO}_{2}$ and IRMOF-1 are shown in figure 6. 3.2b $Z n(N D C)(D P M B I) M O F: \quad$ Here, $\mathrm{NDC}=2,7-$ naphthalene dicarboxylate, and DPMBI $=$ N,N'-di-(4pyridylmethyl)-1,2,4,5-benzenetetracarboxydiimide).

The adsorption isotherm of $\mathrm{CO}_{2}$ in this MOF calculated from MCIN is compared against experimental data ${ }^{46}$ in figure 7. Here too, the intermolecular arrangement of adsorbed $\mathrm{CO}_{2}$ molecules as well as the favorable interaction sites of $\mathrm{CO}_{2}$ with the $\mathrm{Zn}(\mathrm{NDC})$ (DPMBI) MOF have been examined. Several PCFs have been calculated at $298 \mathrm{~K}$ and $0.05,0.4$ and $0.8 \mathrm{~atm}$. Intermolecular PCFs between adsorbed $\mathrm{CO}_{2}$ molecules at three pressures are shown in figure 8 . The peak magnitude of $\mathrm{g}_{\mathrm{C}-\mathrm{C}}(\mathrm{r}), \mathrm{g}_{\mathrm{C}-\mathrm{O}}(\mathrm{r})$ and corresponding coordination numbers increase with increasing pressure. At $0.8 \mathrm{~atm}$ pressure, around $1.2 \mathrm{CO}_{2}$ molecules are observed in the first coordination shell of any $\mathrm{CO}_{2}$ molecule. Based on MOF- $\mathrm{CO}_{2}$ PCFs obtained at the lowest pressure $(0.05 \mathrm{~atm})$, the following favorable interactions between adsorbed $\mathrm{CO}_{2}$ and $\mathrm{Zn}(\mathrm{NDC})(\mathrm{DPMBI})$ are identified: i) $\mathrm{O}$ of $\mathrm{CO}_{2}$ and $\mathrm{H}$ of the NDC linker of the MOF (weak hydrogen bonding), ii) $\mathrm{C}$ of $\mathrm{CO}_{2}$ and $\mathrm{O}$ of carboxylate groups of linker (Lewis acid-base interaction), and iii) center of mass of pyridine rings and the $\mathrm{O}$ of the $\mathrm{CO}_{2}(\pi-\pi$ interaction). As before, these interactions have been identified on established 


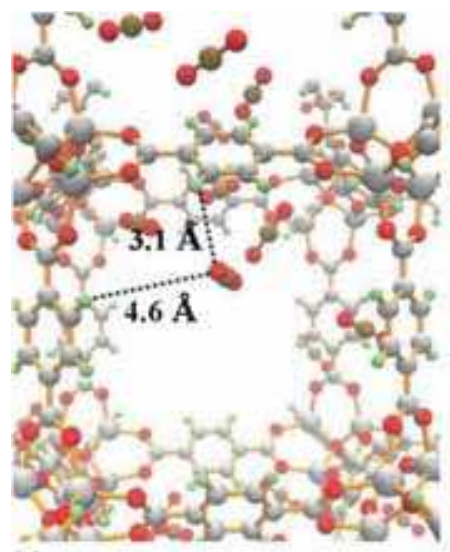

(a)

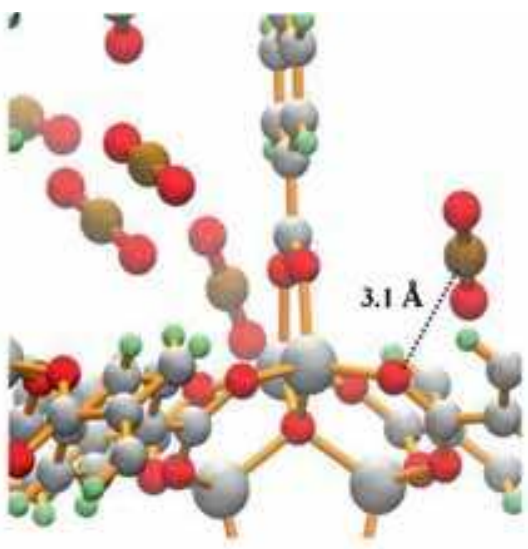

(b)

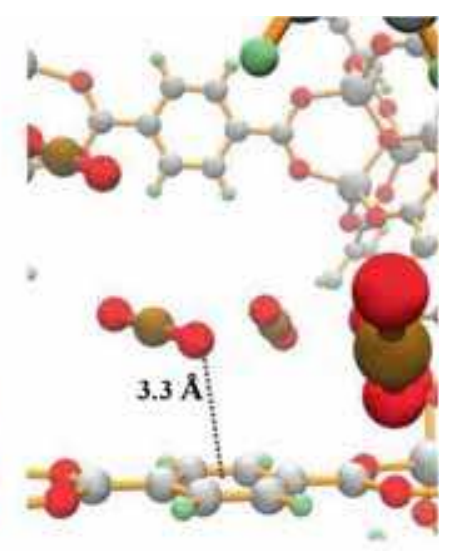

(c)

Figure 6. Interactions between a) $\mathrm{H}$ of $\mathrm{MOF}$ and $\mathrm{O}$ of $\left.\mathrm{CO}_{2} ; \mathrm{b}\right) \mathrm{O}$ of $\mathrm{MOF}$ and $\mathrm{C}$ of $\mathrm{CO}_{2}$; and c) center of mass of phenyl ring and $\mathrm{O}$ of $\mathrm{CO}_{2}$ at $298 \mathrm{~K}$ and $4 \mathrm{~atm}$ in IRMOF-1. Color scheme: MOF atoms: C-Silver, O-red, H-green, Zn-iceblue and $\mathrm{CO}_{2}$ : C-tan and O-red.



Figure 7. Adsorption isotherms of $\mathrm{CO}_{2}$ in $\mathrm{Zn}(\mathrm{NDC})$ (DPMBI) at $298 \mathrm{~K}$ calculated through MCIN (blue circles) compared with experimental (brown squares) data. ${ }^{46}$

geometric criteria alone. ${ }^{59-62}$ The corresponding PCFs have been calculated at $0.05,0.4$ and $0.8 \mathrm{~atm}$ and are shown in figure 9a-c. In figure 9a, the peak at $3.2 \AA$ corresponds to the interaction of $\mathrm{O}$ of $\mathrm{CO}_{2}$ with one of the $\mathrm{H}$ of NDC linker ring. In figure $9 \mathrm{~b}$, the peak at
$4.2 \AA$ corresponds to the $\mathrm{C}$ of $\mathrm{CO}_{2}$ interacting with the $\mathrm{O}$ of the carboxylate group of linkers (NDC or DPMBI) via Lewis acid-base interactions. In figure 9b, the peak height increases with pressure unlike the behavior seen in IRMOF-1 (figure 5b). In Zn(NDC)(DPMBI) MOF, $\mathrm{O}$ of carboxylic groups are directed towards the pore which is the entropically dominant region. ${ }^{63}$ Thus, $\mathrm{CO}_{2}$ prefers this location at high pressures. However, in IRMOF-1, O of carboxylate groups are at the corners of the pores which is the energetically favorable domain. Thus, at high pressures, $\mathrm{CO}_{2}$ prefers to bind in the entropically dominant region and the peak height decreases with increasing pressure (figure 5b). In figure $9 \mathrm{c}$, the peak at $5 \AA$ corresponds to $\pi-\pi$ interaction between the pyridine ring of DPMBI and $\mathrm{CO}_{2}$. These interactions between $\mathrm{CO}_{2}$ and the framework atoms can be visualized in figure 10 .

\section{2c Perfluorinated Conjugated Microporous Polymer:} MD simulations using a force field were carried out on a model compound, fluorine substituted tetraphenylethylene


Figure 8. Intermolecular pair correlation functions between sites of adsorbed $\mathrm{CO}_{2}$ molecules in $\mathrm{Zn}(\mathrm{NDC})(\mathrm{DPMBI}) \mathrm{MOF}$ a) $\mathrm{C}-\mathrm{C}$; and b) $\mathrm{C}-\mathrm{O}$ at $298 \mathrm{~K}$ and $0.05 \mathrm{~atm}$, $0.4 \mathrm{~atm}$, and $0.8 \mathrm{~atm}$. 
(a)

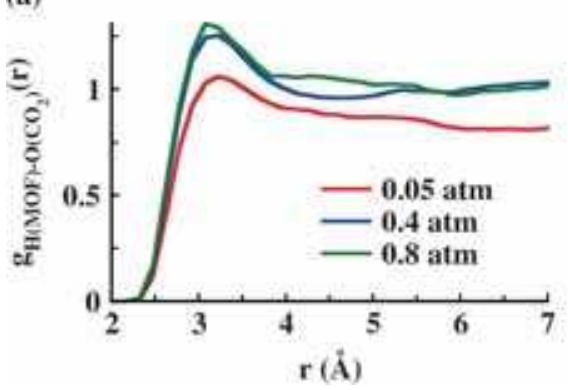

(b)

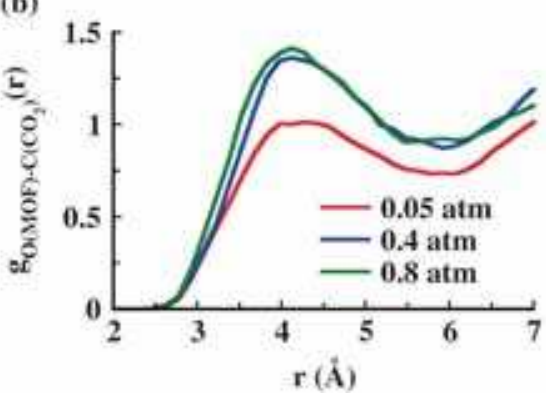

(c)



Figure 9. Pair correlation functions between a) $\mathrm{H}$ of $\mathrm{MOF}$ and $\mathrm{O}$ of $\mathrm{CO}_{2}$; b) $\mathrm{O}$ of $\mathrm{MOF}$ and $\mathrm{C}$ of $\mathrm{CO}_{2}$; and c) center of mass of pyridine ring $(\mathrm{X})$ and $\mathrm{O}$ of $\mathrm{CO}_{2}$ at $298 \mathrm{~K}$ and different pressures: $0.05 \mathrm{~atm}, 0.4 \mathrm{~atm}$, and $0.8 \mathrm{~atm}$. The MOF is $\mathrm{Zn}(\mathrm{NDC})(\mathrm{DPMBI}) \mathrm{MOF}$.

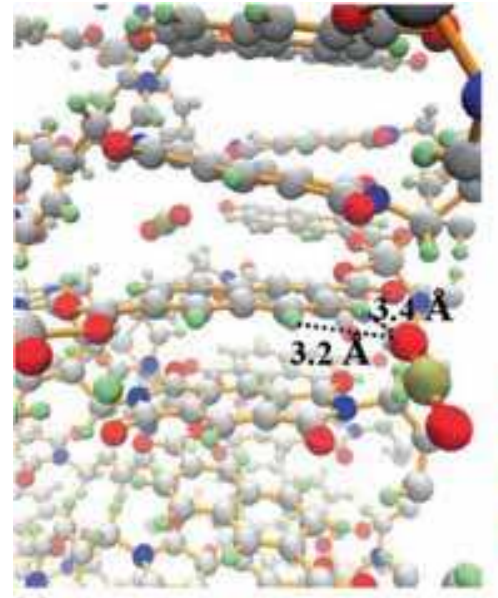

(a)

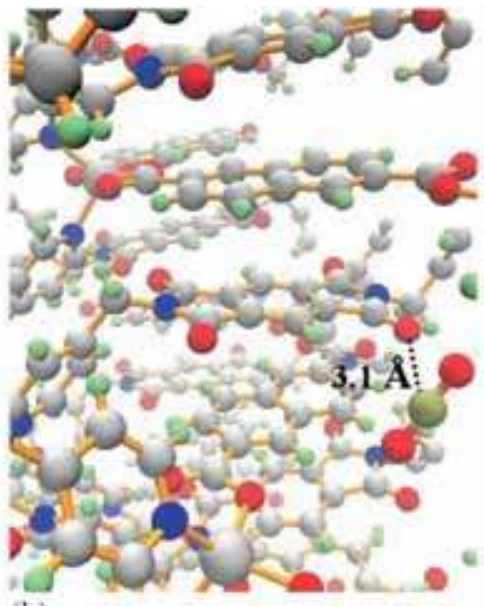

(b)

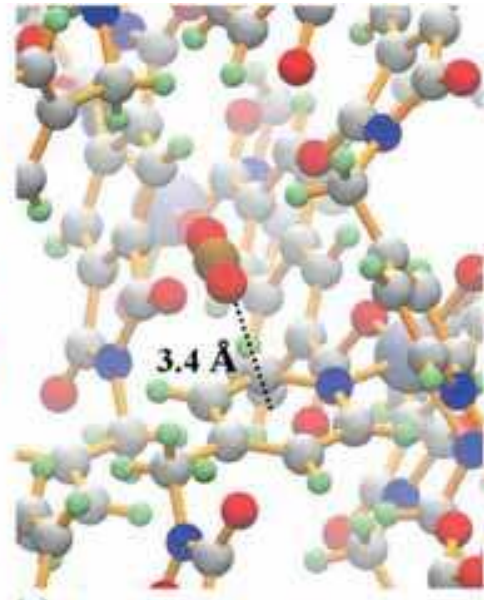

(c)

Figure 10. Interactions between a) $\mathrm{H}$ of $\mathrm{MOF}$ and $\mathrm{O}$ of $\left.\mathrm{CO}_{2} ; \mathrm{b}\right) \mathrm{O}$ of $\mathrm{MOF}$ and $\mathrm{C}$ of $\mathrm{CO}_{2}$; and c) center of mass of pyridine ring and $\mathrm{O}$ of $\mathrm{CO}_{2}$ at $298 \mathrm{~K}$ and 0.05 atm in $\mathrm{Zn}(\mathrm{NDC})(\mathrm{DPMBI}) \mathrm{MOF}$. Color scheme: MOF atoms: C-silver, O-red, $\mathrm{H}$-green, $\mathrm{Zn}$-iceblue and $\mathrm{CO}_{2}$ : C-tan, O-red.

based conjugated microporous polymer, TPE-FCMP (1) as discussed in Supporting Information. 1 was characterized through calculations of powder X-ray diffraction (PXRD), accessible surface area (ASA) and adsorption isotherm of $\mathrm{CO}_{2}$. The density of the initial model obtained using MD simulations is $1.1 \mathrm{~g} / \mathrm{cc}$. The accessible surface area of this model structure was calculated using a Monte Carlo code developed by Snurr and co-workers. ${ }^{64}$ Employing a value of $3.681 \AA$ for the probe diameter of $\mathrm{N}_{2}$, the ASA for the $1.1 \mathrm{~g} / \mathrm{cc}$ CMP model was calculated to be $481 \mathrm{~m}^{2} / \mathrm{g}$. In general, CMPs are kinetically controlled structures and do not show long range periodicity, unlike MOFs and covalent organic frameworks (COFs) ${ }^{65-67}$ In our earlier work on TPE-CMP, the density of the modelled structure was decreased by $20 \%$ in order to match the accessible surface $\operatorname{area}^{50}$ determined experimentally. The same procedure was applied herein to TPE-FCMP. The density of 1 was decreased to $0.89 \mathrm{~g} / \mathrm{cc}$, in steps. At each step, post energy minimization, MD simulations for over $2 \mathrm{~ns}$ was carried out and subsequently, the ASA was recalculated. The calculated ASA of the structure at $0.89 \mathrm{~g} / \mathrm{cc}$ density was found to be $867 \mathrm{~m}^{2} / \mathrm{g}$. The PXRD pattern of the $0.89 \mathrm{~g} / \mathrm{cc}$ structure was calculated (see Supplementary Information for more details) with a resolution of $0.11 \AA^{-1}$ and is shown in figure S16. One of the oligomer in TPE-FCMP is highlighted in figure S14. To understand the connectivity among the pores and void spaces, $\mathrm{N}_{2}$ accessible surface (with a probe radius of $1.82 \AA)^{68}$ was estimated using Mercury ${ }^{69}$ and the same is shown in figure $11 \mathrm{a}$, where the void space architecture in the polymer is shown in yellow. The total void volume is estimated to be about $36 \%$ of the simulation cell.

3.2d GCMC simulations of $\mathrm{CO}_{2}$ in 1: GCMC simulation results reported here were carried out using MCIN, ${ }^{70,71}$ as discussed in section S4 of Supporting Information. In our simulations, both the polymer and 


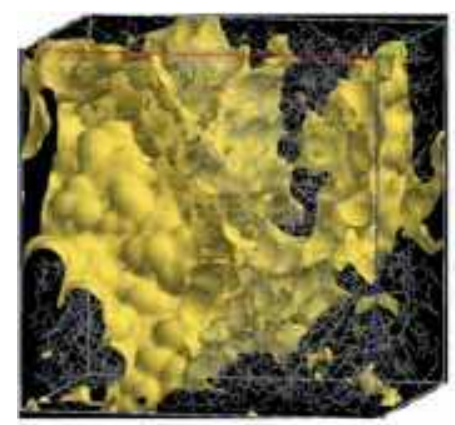

(a)

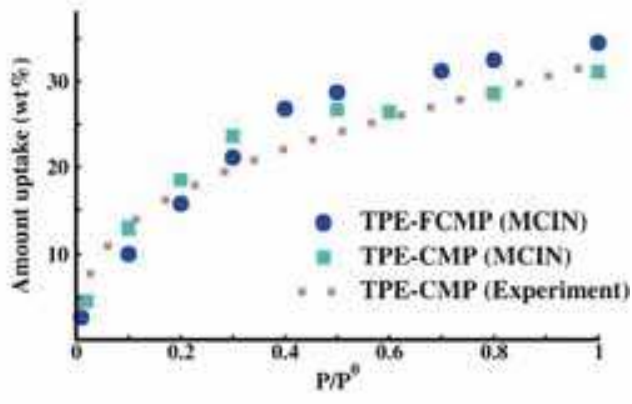

(b)

Figure 11. a) Pore architecture in model TPE-FCMP. Yellow region indicates the void space for $\mathrm{N}_{2}$ while $\mathrm{C}$ and $\mathrm{H}$ atoms of the polymer are in grey and white colors respectively. b) Adsorption isotherms for $\mathrm{CO}_{2}$ in conjugated microporous polymers at $195 \mathrm{~K}$. Experimental data for TPE-CMP 50 (brown dotted line); Blue circles and cyan squares are results from MCIN in TPE-FCMP and TPE-CMP respectively.

$\mathrm{CO}_{2}$ were assumed to be rigid. The calculated adsorption isotherm of $\mathrm{CO}_{2}$ in TPE-FCMP (1), TPE-CMP and the latter's experimental uptake ${ }^{50}$ are compared in figure $11 \mathrm{~b}$. Our calculations predict a $10 \%$ increase in the uptake of $\mathrm{CO}_{2}$ in the perfluorinated polymer over its hydrogenated counterpart.

Adsorption isotherms of $\mathrm{CO}_{2}$ in IRMOF-1 $(298 \mathrm{~K})$, $\mathrm{Zn}$ (NDC)(DPMBI) (298 K) and TPE-CMP (195 K) calculated using both DREIDING and UFF force fields (for the adsorbent) are presented in figures S9, S10 and S15, respectively. Experimentally determined isotherms are also provided. The amount of $\mathrm{CO}_{2}$ uptake calculated using the UFF force field for the adsorbent is marginally higher than that of either the DREIDING prediction or experiment.

To understand the arrangement of adsorbed $\mathrm{CO}_{2}$ molecules near the nodes as well as linkers in the TPE-FCMP polymer, their spatial distribution in the matrix was studied at three pressures: $0.1,0.5$ and $1.0 \mathrm{~atm}$. In typical MOF simulations, such spatial density maps are averaged over ensemble and time. However, all the nodes and linkers are not present in the same environment in 1. It lacks long range periodicity and nodes or linkers line present along the pore surface have a different environment than those lying in the core of the polymer matrix. Thus, we have chosen to examine the locations of $\mathrm{CO}_{2}$ around a specifically chosen tetraphenylethene (node) and a 4,4'-diethynyloctafluorobiphenyl (linker) moiety which were identified visually to lie on a pore surface. These were obtained via constant-NVT MD simulations carried out for $15 \mathrm{~ns}$ each at a temperature of $195 \mathrm{~K}$ in a fixed polymer framework. Isosurfaces of $\mathrm{CO}_{2}$ density with respect to either the node or the linker present on the pore surface are displayed in figure $12 \mathrm{a}-\mathrm{f}$. The cheese colored region indicates the distribution of $\mathrm{CO}_{2}$. The maps demonstrate that $\mathrm{CO}_{2}$ interacts with the phenyl and ethylenic groups of the node and with the phenyl and acetylenic groups of the linker.

\subsection{Comparison of GCMC results with $M D$ simulations}

Results from MCIN, in terms of adsorption isotherms were compared against experimental data above. Neutron and X-ray scattering experiments can provide information on intermolecular structure of molecules adsorbed in MOF solids. However, these experiments are challenging and thus are very rare. ${ }^{72-74}$ Thus, we compare the intermolecular structure obtained from MCIN against results from MD simulations. A key quantity to characterize is the pair correlation function, results of which are presented here.

In these simulations, DREIDING and TraPPE force fields were used to model the IRMOF- 1 and $\mathrm{CO}_{2}$ in their all-atom representations respectively. $\mathrm{CO}_{2}-\mathrm{CO}_{2}$ structural correlations were calculated at a pressure of $10 \mathrm{~atm}$. At this pressure, the variation in the number of adsorbed $\mathrm{CO}_{2}$ molecules with $\mathrm{MC}$ cycles is shown in figure $\mathrm{S} 25$. The number of $\mathrm{CO}_{2}$ molecules fluctuate around a mean value of $86 . \mathrm{CO}_{2}-\mathrm{CO}_{2}$ pair correlation functions obtained from $\mathrm{MD}$ simulations performed with 86 molecules in the MOF did not quite match those obtained from the GCMC simulations. The issue was resolved to the fact that the GCMC run had significant fluctuations in the number of molecules while the MD run was performed in the canonical ensemble. Needless to state, the difference is a consequence of the fact that one is not in the thermodynamic limit. We 


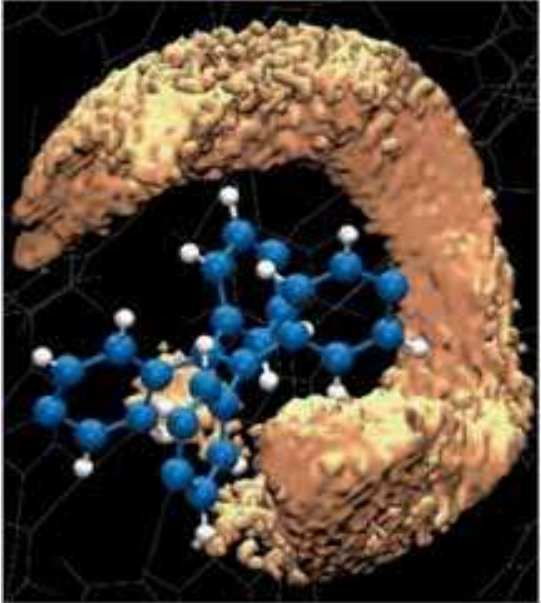

(a)

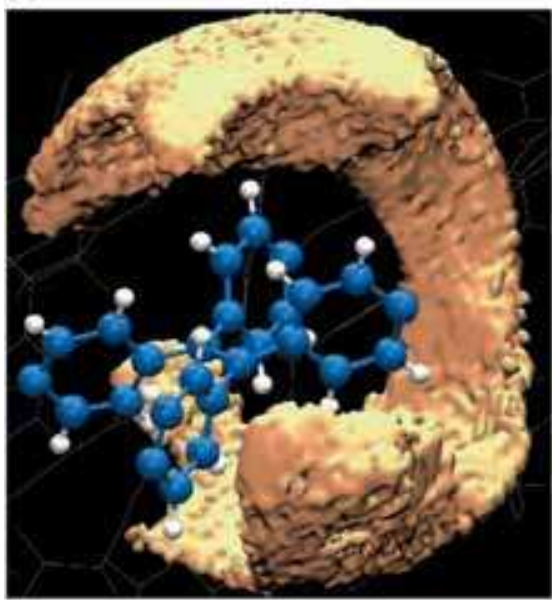

(c)

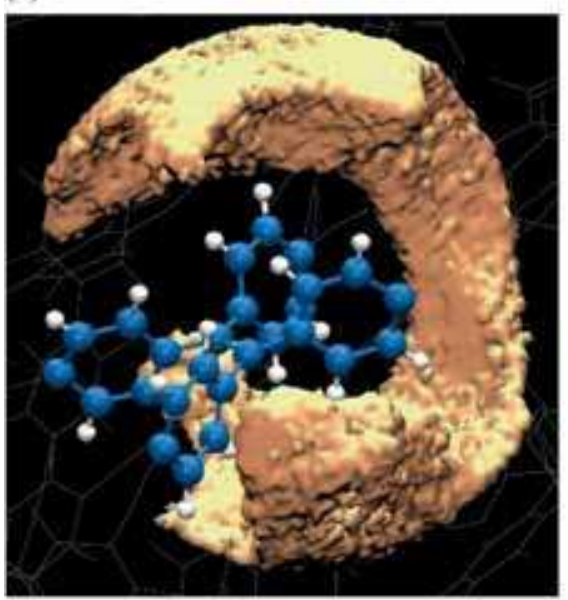

(e)

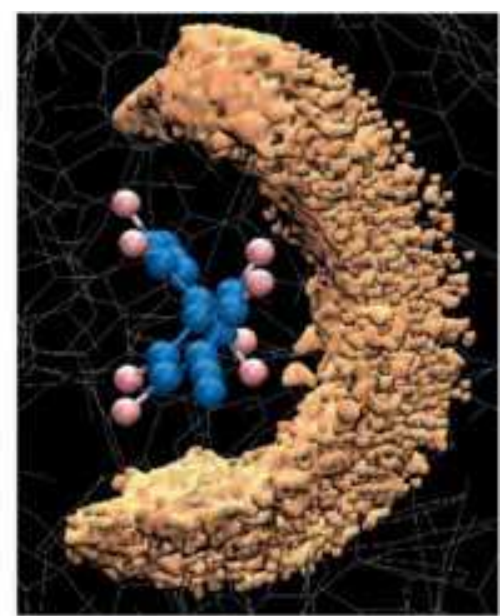

(b)

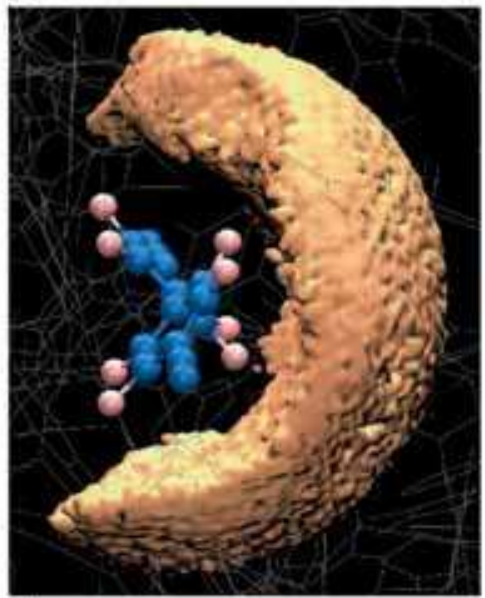

(d)

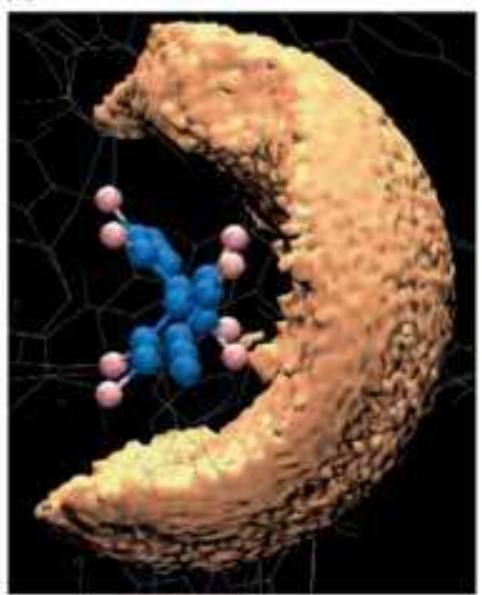

(f)

Figure 12. (a, c, e/b, d, f ) Spatial density distribution maps of $\mathrm{CO}_{2}$ around a specific node and linker in TPE-FCMP at $195 \mathrm{~K}$ around a specific node/linker at $0.1,0.5$ and $1.0 \mathrm{~atm}$ respectively. Cheese colored surfaces show possible locations of $\mathrm{CO}_{2}$ at an isosurface value of $5 \times 10^{-4}$ a.u. Blue and tan colors are $\mathrm{C}$ and $\mathrm{H}$ atoms of the node and the linkers in the polymer respectively. Rest of the CMP atoms are shown as thin lines.

obtained the probability distribution (histogram) of the number of molecules from the GCMC simulation and performed six independent MD simulations, each in the
NVT ensemble but with different number of molecules ranging between 60 and 120. Pair correlation functions obtained from each of these runs were weighted (via 
the histogram obtained from the GCMC run) and a mean pair correlation function was obtained which is compared to that from the GCMC run in figure S17ad. They match rather well, giving confidence on the configurational sampling in MCIN.

Furthermore, we characterized the vibrational, orientational and diffusive properties of $\mathrm{CO}_{2}$ molecules in IRMOF-1. Low frequency infrared spectrum provides a precise understanding on the nature of interaction between probe molecules e.g., $\mathrm{CO}, \mathrm{NO}$, and $\mathrm{CO}_{2}$, etc., with the MOF. ${ }^{75}$ Herein, vibrational density of states were calculated to delineate the intermolecular modes of adsorbed $\mathrm{CO}_{2}$ in IRMOF-1.

3.3a Vibrational density of states: The vibrational density states (VDOS) have been calculated to understand intermolecular 'modes' of adsorbed $\mathrm{CO}_{2}$ in IRMOF-1 at 10, 20 and $30 \mathrm{~atm}$ and $298 \mathrm{~K}$. Details of the calculations are provided in Supplementary Information. The low frequency band to intermolecular 'modes' exhibits a blue shift with increasing pressure which is shown in figure S18.

A key character of adsorbed gases in framework solids is cooperativity. Although in general the isosteric heat of adsorption decreases with increasing coverage, under certain circumstances, it can show an increase (followed by a decrease). This occurs due to favorable interaction between the adsorbed gas molecules, a feature called as cooperativity in the literature. ${ }^{76,77}$ Cooperativity between $\mathrm{CO}_{2}$ adsorbed in IRMOF-1 was studied by examining the intermolecular angle distribution between neighboring molecules at $298 \mathrm{~K}$ and $10 \mathrm{~atm}$. This distribution was compared with that obtained from bulk $\mathrm{CO}_{2}$. Molecules confined within narrow pores, with pore widths of a few molecular diameters, can exhibit a wide range of physical behavior. ${ }^{78,79}$ The introduction of wall forces, and the competition between fluid-wall and fluid-fluid forces, can lead to interesting surface-driven phase changes. ${ }^{80-84}$ These include new kinds of phase transitions not found in the bulk phase. Recently, Snurr et al., have calculated the density of $\mathrm{CO}_{2}$ in IRMOF-1 and compared the same with that of bulk $\mathrm{CO}_{2}$ at $298 \mathrm{~K} .{ }^{57}$ However, the orientational distribution between adsorbed $\mathrm{CO}_{2}$ molecules has not been studied yet, to our knowledge.

3.3b $\mathrm{CO}_{2}$ orientation: The orientational ordering between near neighbour adsorbed $\mathrm{CO}_{2}$ molecules in IRMOF-1 was calculated from the configurations obtained from MCIN at $298 \mathrm{~K}$ and $10 \mathrm{~atm}$. An illustration of a typical near-neighbour configuration is shown in figure 13. To aid further discussion, we provide the

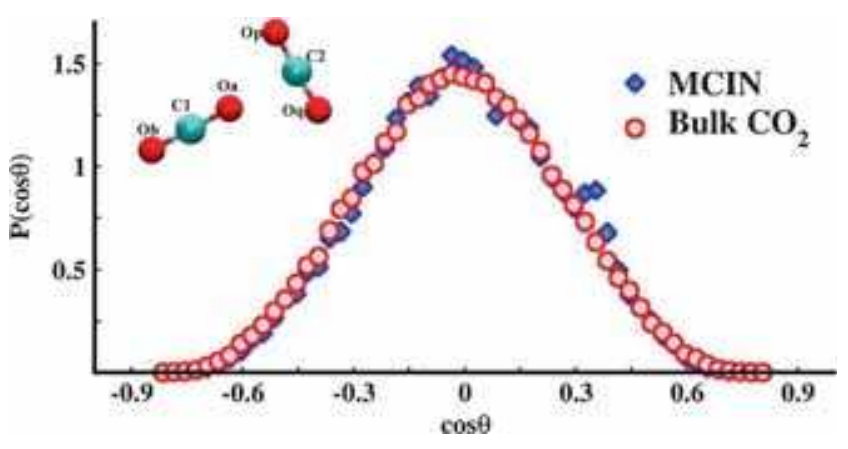

Figure 13. Probability distribution of angles between $\overrightarrow{\mathrm{O}_{p} \mathrm{O}_{q}}$ and $\overrightarrow{\mathrm{C}_{2} \mathrm{O}_{a}}$ (Inset) obtained for $\mathrm{CO}_{2}$ in IRMOF-1 from MCIN and from MD simulations of bulk $\mathrm{CO}_{2}$ at $298 \mathrm{~K}$ and $1.1 \mathrm{~g} / \mathrm{cc}$. Inset: Illustration of a typical near-neighbor arrangement of $\mathrm{CO}_{2}$ molecules. The carbon of the central molecule is denoted as $\mathrm{C} 2$ and the oxygen atom from another molecule closest to it is denoted as Oa.

Table 2. Self-diffusion coefficients of $\mathrm{CO}_{2}$ in IRMOF1 at $298 \mathrm{~K}$.

\begin{tabular}{lc}
\hline Pressure $(\mathrm{atm})$ & Diffusion Coefficient $\left(\times 10^{-8} \mathrm{~m}^{2} / \mathrm{s}\right)$ \\
\hline 10 & 6.8 \\
20 & 3.9 \\
30 & 3.1 \\
\hline
\end{tabular}

Table 3. Self-diffusion coefficients of $\mathrm{CO}_{2}$ in TPEFCMP at $195 \mathrm{~K}$.

\begin{tabular}{ll}
\hline Pressure $(\mathrm{atm})$ & Diffusion Coefficient $\left(\times 10^{-9} \mathrm{~m}^{2} / \mathrm{s}\right)$ \\
\hline 0.1 & 1.3 \\
0.5 & 1.0 \\
1.0 & 0.7 \\
\hline
\end{tabular}

following nomenclature. The probability distributions of the angle was calculated between $\overrightarrow{O_{p} O_{q}}$ and $\overrightarrow{C_{2} O_{a}}$, where $\mathrm{O}_{\mathrm{a}}$ is the closest oxygen atom to the central carbon $\mathrm{C}_{2}$. The analysis has been carried out for molecules lying within a distance of $3.4 \AA$ which defines the first coordination shell as seen from the $\mathrm{C}-\mathrm{O} \mathrm{g}_{\mathrm{CO}}(\mathrm{r})$ in fluid $\mathrm{CO}_{2}{ }^{85}$

Simultaneously, for the sake of comparison, classical NVT-MD simulations of bulk $\mathrm{CO}_{2}$ were carried out using LAMMPS ${ }^{86}$ with a time step of $1 \mathrm{~ns}$ at $298 \mathrm{~K}$. The EPM2 ${ }^{87}$ potential model was employed for $\mathrm{CO}_{2}$. A good match between the $\mathrm{g}_{\mathrm{CO}}(\mathrm{r})$ of bulk $\mathrm{CO}_{2}$ and that in the IRMOF-1 (via MCIN) was obtained at a bulk density of $1.1 \mathrm{~g} / \mathrm{cc}$ as shown in figure $\mathrm{S} 21$. The probability distribution of angles between the vectors $\overrightarrow{O_{p} O_{q}}$ and $\overrightarrow{\mathrm{C}_{2} \mathrm{O}_{a}}$ was calculated. A comparison between the data in bulk $\mathrm{CO}_{2}$ and that confined in IRMOF-1 is displayed in figure 13. The distributions in figure 13 
exhibit a preference for $\cos \theta$ values around zero indicating that the closest neighboring molecules prefer a distorted T-shaped configuration. This feature in the near-neighbour arrangement between $\mathrm{CO}_{2}$ neighbors is comparable between the adsorbed and bulk phases.

Diffusion behavior of gases is of paramount importance in many applications that are envisioned for porous materials. ${ }^{14,88-92}$ The self-diffusion coefficients of $\mathrm{CO}_{2}$ have been studied in IRMOF-1 as well as TPEFCMP at various pressures. Details of the calculations are provided in Supporting Information. As expected, the diffusion coefficients of $\mathrm{CO}_{2}$ decrease with increasing pressure, and these are shown in tables 2 and 3.

\section{Conclusions}

Adsorption isotherms for $\mathrm{CO}_{2}$ in many metal organic framework solids obtained from GCMC simulations were presented here. The calculated isotherms compare very well with experimentally determined ones, up to 1 atm pressure. Intermolecular structural correlations between the $\mathrm{CO}_{2}$ molecules present within their micropores were also investigated. They exhibited considerable similarities with those observed in bulk fluid $\mathrm{CO}_{2}$. Specific sites of adsorption existing in metal organic framework solids with which $\mathrm{CO}_{2}$ interacts have been identified. These include: fluorine, phenyl and carboxylate groups. van der Waals, Lewis acid-base, weak hydrogen bonding and $\pi-\pi$ interactions determine the adsorption of $\mathrm{CO}_{2}$ in these solids; this understanding can aid in the design of other novel architectures involving such functional groups. Apart from the surface chemistry of the pores, the pore architecture too determines gas uptake, as exemplified by differences in the dependence of $\mathrm{g}_{\mathrm{CO} 2-\mathrm{O}}(\mathrm{r})$ on pressure in two MOFs studied here. Such pair correlation functions can in principle be obtained through neutron scattering experiments and we hope our work would spur more efforts in this area. $^{73,74,93-95}$

We have also been able to predict the uptake of $\mathrm{CO}_{2}$ in a model microporous, amorphous polymer. Perfluorination is shown to increase $\mathrm{CO}_{2}$ uptake by at least $10 \%$. It remains to be seen if this perfluorinated polymer can be synthesized and its $\mathrm{CO}_{2}$ uptake be measured for a comparison to the simulation results presented here. The closest interaction sites for $\mathrm{CO}_{2}$ in this polymer are located at the pore surface lined by the linkers.

For the systems studied here, the UFF force field (for the adsorbent) predicts a marginally higher gas uptake than that obtained from the DREIDING force field.
The latter is able to quantitatively reproduce experimentally determined isotherms. The current Monte Carlo simulations have been performed within a rigid framework approximation. However, organic linkers in MOFs can in particular show some degree of conformational flexibility which can modulate gas uptake at ambient conditions. ${ }^{21}$ In the systems studied herein, the absence of flexibility of the framework appears not to influence amount of gas adsorption. Yet, we plan to implement methods to introduce flexibility to the adsorbent within MCIN, in future. ${ }^{96}$

We are interested in predicting model MOF compounds which are not only $\mathrm{CO}_{2}$-philic but are also stable in the presence of water vapor. This aspect will constitute our future endeavours.

\section{Supplementary Information}

The Supplementary Information associated with this article has sections containing the development of MCIN code and applications of MCIN: validation of MCIN by reproducing simulated and experimental adsorption isotherms, modelling $\mathrm{CO}_{2}$ adsorption in TPE-FCMP, comparison of pair correlation functions of $\mathrm{CO}_{2}$ with respect to MOF sites obtained from MCIN and LAMMPS, vibrational density of states of $\mathrm{CO}_{2}$ in IRMOF-1 and $\mathrm{CO}_{2}$ diffusion in IRMOF-1 and TPEFCMP at various pressures, comparison of pair correlation functions of adsorbed $\mathrm{CO}_{2}$ with bulk $\mathrm{CO}_{2}$, comparison pair correlation functions of $\mathrm{CH}_{4}$ in FMOF-1 and $\left[\mathrm{Zn}_{2}(\mathrm{~L})\right]_{\infty}$ at various pressures and running coordination number of $\mathrm{CO}_{2}$ around carboxylate group of IRMOF-1. The Supplementary Information for this article is available at http://www.ias.ac.in/chemsci.

\section{Acknowledgements}

We thank DST for support. The first author acknowledges CSIR for a research fellowship. The second author acknowledges SSL for a Senior Fellowship. We thank Prof. Tapas Kumar Maji and his research group at JNCASR for many insightful discussions.

\section{References}

1. Düren T, Bae Y-S and Snurr R Q 2009 Chem. Soc. Rev. 381237

2. Rowsell J L C, Millward A R, Park K S and Yaghi O M 2004 J. Am. Chem. Soc. 1265666

3. Getman R B, Miller J H, Wang K and Snurr R Q 2011 J. Phys. Chem. C 1152066

4. Kumar A V A, Jobic H and Bhatia S K 2006 J. Phys. Chem. B 11016666

5. Siriwardane R V, Shen M S and Fisher E P 2003 Energy Fuels 17571 
6. Economides M J and Wood D A 2009 J. Nat. Gas Sci. Eng. 11

7. Wang W, Ma C, Lin P, Sun L and Cooper A I 2013 Energy Environ. Sci. 6105

8. Prajwal B and Ayappa K 2014 Adsorption 20769

9. Arenillas A, Smith K, Drage T and Snape C 2005 Fuel 842204

10. Haldar R, Narayan R, Pradeep R and Maji T K 2012 Indian J. Chem., Sec A 51A 1231

11. Myers A and Monson 2014 Adsorption 20591

12. Belmabkhout Y, Frére M and Weireld G D 2004 Meas. Sci. Technol. 15

13. Nakashima $M$, Shimada $S$, Inagaki $M$ and Centeno $T$ 1995 Carbon 331301

14. Bao Z, Yu L, Ren Q, Lu X and Deng S 2011 J. Colloid Interface Sci. 353549

15. Fischer M and Bell R G 2012 J. Phys. Chem. C 116 26449

16. Liu Z, Horikawa T, Do D and Nicholson D $2012 \mathrm{~J}$. Colloid Interface Sci. 368474

17. Torrisi A, Bell R G and Mellot-Draznieks 2010 Cryst. Growth Des. 102839

18. Naumov S, Valiullin R, Kaürger J and Monson P 2009 Phys. Rev. E 80031607

19. Mowat J P S, Seymour V R, Griffin J M, Thompson S P, Slawin A M Z, Fairen-Jimenez D, Düren T, Ashbrook S E and Wright P A 2012 Dalton Trans. 413937

20. Chen L, Grajciar L, Nachtigall P and Düren T $2011 \mathrm{~J}$. Phys. Chem. C 11523074

21. Kanoo P, Reddy S K, Kumari G, Haldar R, Narayana C, Balasubramanian S and Maji T K 2012 Chem. Commun. 488487

22. Yang Q, Liu D, Zhong C and Li J R 2013 Chem. Rev. 1138261

23. Purton C J and Parker S 2013 Mol. Simul. 391240

24. Dubbeldam D, Torres-Knoop A and Walton K S 2013 Mol. Simul. 391253

25. Nicholson D and Parsonage N G 1982 In Computer simulation and the statistical mechanics of adsorption (Academic Press: London)

26. Esselink K, Loyens L D J C and Smit B 1995 Phys. Rev. E 511560

27. Bates S P, Van Well W J M, Van Santen R A and Smit B 1997 Mol. Simul. 19301

28. Smit B and Krishna R 2001 Curr. Opin. Solid State Mater. Sci. 5455

29. Kim J and Smit B 2012 J. Chem. Theory Comput. 82336

30. Snurr R Q, Bell A T and Theodorou D N 1993 J. Phys. Chem. 9713742

31. Severson B L and Snurr R Q 2007 J. Chem. Phys. 126 134701

32. Kowalczyk P, Tanaka H, Kaneko K, Terzyk A P and Do D D 2005 Langmuir 215639

33. Rahimi M, Singh J K, Babu D J, Schneider J J and Müller-Plathe F 2013 J. Phys. Chem. C 11713492

34. Liu J C and Monson P A 2006 Ind. Eng. Chem. Res. 45 5649

35. Malani A and Ayappa K G 2009 J. Phys. Chem. B 113 1058

36. Channon Y M, Catlow C R A, Gorman A M and Jackson R A 1998 J. Phys. Chem. B 1024045

37. Martin M G 2013 Mol. Simul. 391212
38. Kofke D A and Mihalick B C 2002 Fluid Phase Equilib. 194-197327

39. Jorgensen W L and Tirado-Rives J 2005 J. Comput. Chem. 261689

40. Gupta A, Chempath S, Sanborn M J, Clark L A and Snurr R Q 2003 Mol. Simul. 2929

41. Yang C, Kaipa U, Mather Q Z, Wang X, Nesterov V, Venero A F and Omary M A $2011 \mathrm{~J}$. Am. Chem. Soc. 13318094

42. Lin X, Blake A, Wilson J C, Sun X Z, Champness N R, George M W, Hubberstey P, Mokaya R and Schröder M 2006 J. Am. Chem. Soc. 12810745

43. Nijem N, Canepa P, Kaipa U, Tan K, Roodenko K, Tekarli S, Halbert J, Oswald I W H, Arvapally R K, Yang C, Thon- hauser T, Omary M A and Chabal Y J 2013 J. Am. Chem. Soc. 1351261

44. Rappe A K, Casewit C J, Colwell K S, Goddard W A and Skiff W M 1992 J. Am. Chem. Soc. 11410024

45. Martin M G and Siepmann J I 1998 J. Phys. Chem. B 1022569

46. Leong C F, Faust T B, Turner P, Usov P M, Kepert C J, Babarao R, Thornton A W and D'Alessandro D M 2013 Dalton Trans. 429831

47. Potoff J J and Siepmann J I 2001 AIChE J. 471676

48. Mayo S L, Olafson B D and Goddard W A 1990 J. Phys. Chem. 948897

49. Barnes C 2006 In ThermoSolver: An Integrated Educational Thermodynamics Software Program. H.B.S. thesis (Oregon State University Library, Special Collections: Oregon, USA) p. 12

50. Suresh V M, Bonakala S, Roy S, Balasubramanian S and Maji T K 2014 J. Phys. Chem. C 11824369

51. Greathouse J A, Kinnibrugh T L and Allendorf M D 2009 Ind. Eng. Chem. Res. 483425

52. Skoulidas A I and Sholl D S 2005 J. Phys. Chem. B 109 15760

53. Wongsinlatam W and Remsungnen T 2013 J. Chem. 20131

54. Ghoufi A and Maurin G 2010 J. Phys. Chem. C 114 6496

55. Krokidas P, Skouras E, Nikolakis V and Burganos V 2008 Mol. Simul. 341299

56. Humphrey W, Dalke A and Schulten K 1996 J. Mol. Graph 1433

57. Walton K S, Millward A R, Dubbeldam D, Frost H, Low J J, Yaghi O M and Snurr R Q 2008 J. Am. Chem. Soc. 130406

58. Mehio N, Dai S and Jiang D E 2014 J. Phys. Chem. A 1181150

59. Derewenda Z S, Lee L and Derewenda U $1995 \mathrm{~J}$. Mol. Biol. 252248

60. Gautham R D and Thomas S 2001 In The Weak Hydrogen Bond: In Structural Chemistry and Biology (Oxford University Press: London)

61. Hunter C A and Sanders J K M 1990 J. Am. Chem. Soc. 1125525

62. Baburin I A, Blatov V A, Carlucci L, Ciani G and Proserpio D M 2008 Cryst. Eng. Comm. 101822

63. Suraweera N S, Albert J R, Barnes C E and Keffer D J 2014 Int. J. Hydrogen Energy 399241

64. Düren T, Sarkisov L and Snurr R Q 2007 Research section calculating the accessible surface area for nonorthorhombic unit cells (http://people.bath.ac.uk/td222/ research/surface_area/non_ortho/index.html) 
65. Budd P M, Ghanem B S, Makhseed S, McKeown N B, Msayib K J and Tattershall C E 2004 Chem. Commun. 230

66. Jiang J -X, Su F, Trewin A, Wood C D, Niu H, Jones J T A, Khimyak Y Z and Cooper A I 2008 J. Am. Chem. Soc. 1307710

67. Wu P, Wang J, He C, Zhang X, Wang Y, Liu T and Duan C 2012 Adv. Funct. Mater. 221698

68. Jiang J -X, Trewin A, Su F, Wood C D, Niu H, Jones J T A, Khimyak Y Z and Cooper A I 2009 Macromolecules 422658

69. Macrae C F, Edgington P R, McCabe P, Pidcock E, Shields G P, Taylor R, Towler M and van de Streek J 2006 J. Appl. Crystallogr. 39453

70. Allen P and Tildesley D 1987 In Computer simulation of liquids (Oxford science publications, Clarendon Press: New York)

71. Frenkel D and Smit B 2001 In Understanding Molecular Simulation: From Algorithms to Applications 2nd Edition (Academic Press: London)

72. Dubbeldam D, Frost H, Walton K S and Snurr R Q 2007 Fluid Phase Equilib. 261152

73. Queen W L, Bloch E D, Brown C M, Hudson M R, Mason J A, Murray L J, Ramirez-Cuesta A J, Peterson V K and Long J R 2012 Dalton Trans. 414180

74. Wu H, Simmons J M, Srinivas G, Zhou W and Yildirim T 2010 J. Phys. Chem. Lett. 11946

75. Daturi M 2012 Curr. Phys. Chem. 2178

76. Vaidhyanathan R, Iremonger S S, Shimizu G K H, Boyd P G, Alavi S and Woo T K 2012 Angew. Chem., Int. Ed. 511826

77. Kitagawa S and Matsuda R 2007 Coord. Chem. Rev. 251 2490

78. Das C K and Singh J K 2013 J. Chem. Phys. 139174706
79. Liu Z, Do D and Nicholson D 2011 J. Colloid Interface Sci. 361278

80. Page K and Monson P 1996 Phys. Rev. E 546557

81. Malani A, Ayappa K G and Murad S 2009 J. Phys. Chem. B 11313825

82. Kamakshi J and Ayappa K G 2001 Langmuir 175245

83. Ayappa K G and Ghatak C 2002 J. Chem. Phys. 117 5373

84. Malani A and Ayappa K G 2012 Mol. Simul. 381114

85. Saharay M and Balasubramanian S 2007 J. Phys. Chem. B 111387

86. Plimpton S 1995 J. Comput. Phys. 1171

87. Harris J G and Yung K H 1995 J. Phys. Chem. 99 12021

88. Fujita M, Oguro D, Miyazawa M, Oka H, Yamaguchi K and Ken-taro Ogura 1995 Nature 378469

89. Mera H A, Gomez-Ballesteros J L and Balbuena P B 2014 J. Chem. Eng. Data 592973

90. Eslami H, Kesik M, Karimi-Varzaneh H A and MüllerPlathe F 2013 J. Chem. Phys. 139124902

91. Bhatia S K and Myers A L 2006 Langmuir 221688

92. Plant D F, Maurin G and Bell R G 2007 J. Phys. Chem. B 1112836

93. Rosi N L, Eckert J, Eddaoudi M, Vodak D T, Kim J, O'Keeffe M and Yaghi O M 2003 Science 3001127

94. Queen W L, Hudson M R, Bloch E D, Mason J A, Gonzalez M I, Lee J S, Gygi D, Howe J D, Lee K, Darwish T A, James M, Peterson V K, Teat S J, Smit B, Neaton J B, Long J R and Brown C M 2014 Chem. Sci. 54569

95. Ogilvie S H, Duyker S G, Southon P D, Peterson V K and Kepert C J 2013 Chem. Commun. 499404

96. MCIN is available for academic users on request by email to the Corresponding Author 